\title{
Evaluation of the magnetic permeability for the microstructural characterization of a duplex stainless steel
}

Edgard de M. Silva ${ }^{1}$, Josinaldo P. Leite ${ }^{2}$, Francisco A. de França Neto ${ }^{1}$, João P. Leite ${ }^{2}$, Walter M. L. Fialho ${ }^{2}$, Victor Hugo C. de Albuquerque ${ }^{3}$, João Manuel R. S. Tavares ${ }^{4}$

${ }^{1}$ Instituto Federal de Educação Ciência e Tecnologia da Paraíba, João Pessoa/PB, Brazil Email: edgard@ifpb.edu.br, fafn@ifpb.edu.br

${ }^{2}$ Universidade Federal da Paraíba, João Pessoa/PB, Brazil

Email: josinaldo@ct.ufpb.br, joao.leite100@yahoo.com.br,wmlfialho@yahoo.com.br

${ }^{3}$ Programa de Pós-Graduação em Informática Aplicada, Universidade de Fortaleza, Fortaleza/CE, Brazil

Email: victor.albuquerque@unifor.br

${ }^{4}$ Instituto de Engenharia Mecânica e Gestão Industrial, Departamento de Engenharia Mecânica, Faculdade de Engenharia, Universidade do Porto, Porto, Portugal

Email: tavares@fe.up.pt

\section{Corresponding author:}

Prof. João Manuel R. S. Tavares

Faculdade de Engenharia da Universidade do Porto

Rua Dr. Roberto Frias, s/n

4200-465 Porto, PORTUGAL

email: tavares@fe.up.pt

Phone: +351 22 5081487, Fax: +351 225081445 


\title{
Evaluation of the magnetic permeability for the microstructural characterization of a duplex stainless steel
}

\begin{abstract}
Non-Destructive Testing has been commonly used to assess the presence of discontinuities that may affect the integrity of materials in service. In this study, a Hall effect sensor is used in a methodology developed to study in a non-destructive manner the microstructural variations of a material that occur due to the single-phase decomposition. The material selected was the UNS S31803 duplex stainless steel, particularly due to its behavior under temperatures below $525^{\circ} \mathrm{C}$. Measurements of magnetic permeability based on Hall voltage values were performed as well as hardness measurements and X-ray diffraction studies. The results confirm that the magnetic permeability can be used to successfully track the formation of $\alpha^{\prime}$ phase from $\alpha$ phase in a duplex stainless steel.
\end{abstract}

Keywords: Magnetic permeability; Hall voltage; Duplex stainless steel; UNS S31803. 


\section{Introduction}

Techniques based on magnetic flux loss have been commonly used to detect superficial or internal discontinuities in ferromagnetic materials frequently used in engineering [1]. In this sense, Hall effect sensors have been used to detect the size and position of cracks, but have also been effective to detect superficial gaps, especially in metallic materials under excitation by alternating current [2]. The Hall effect discovered by Edwin Herbert Hall in 1879, has been known for over a hundred years, but its use has just become feasible in the last three decades with the advent of microelectronic. Since then, it has been used in a wide variety of industrial applications, including in tachometers, switches and in gauges of position, inclination, level, pressure, thickness, current, voltage, power, frequency and magnetic field. The Hall effect is also commonly used in non-destructive testing in the aircraft industry [3].

The use of magnetic properties is widespread in Materials Science. For example, Hall effect sensors have been used in the microstructural characterization of steels subjected to a variety of heat treatments. Samples of SAE 1045 carbon steel undergoing different treatments were exposed to a 300 Gauss field and Hall voltage values were measured [4]. The results showed that the Hall effect based sensor was sensitive to microstructural changes, and that can be effectively used for non-destructive material characterization [4]. These authors also presented the potentiality of Hall voltage values post-processed by a backpropagation artificial neuronal network to identify the treated material microstructures.

The UNS S31803 duplex stainless steel has as main characteristics the high resistance to corrosion and mechanical resistance, which are due to a balanced microstructure with approximately $50 \%$ of ferrite and $50 \%$ of austenite. Nowadays, the use of this material is important in several industries, including petrochemical, food, paper and cellulose, oil and gas industries [5]. However, when exposed to temperatures above $300{ }^{\circ} \mathrm{C}$, this type of steel loses 
toughness and corrosion resistance, due to the fine precipitation of $\mathrm{Cr}$-rich $\alpha$ phase (usually known as $\alpha^{\prime}$ phase) that produces Cr-depleted regions at the nanoscale [5].

Usually, the phases presented in the duplex stainless steels processed at high temperatures, i.e. $\sigma, \chi$, and $\delta$ phases, can only be characterized by destructive techniques such as the ones based on scanning electron microscopy and transmission electron microscopy [6]. Non-destructive techniques have also been studied for application in microstructural characterization, as the ones based on ultrasonic signal and eddy current that have been used in detection of the embrittled phases present in duplex stainless steels at high temperatures.

An experimental study was carried out to evaluate the potential of the ultrasonic technique, i.e. based on ultrasonic velocity and attenuation measurements, to assess the heat aging effects on duplex stainless steel SAF 2205, at temperatures of $425{ }^{\circ} \mathrm{C}$ and $475{ }^{\circ} \mathrm{C}$ for time up to $200 \mathrm{~h}$, as well as in the as received state of the material. Despite the large scatter measurements, both ultrasonic velocity and attenuation increased with the heat aging time, particularly at $475{ }^{\circ} \mathrm{C}$. Thus, it was concluded that this technique is promising and provides relevant contributions towards the accurate characterization of materials and evaluation of their mechanical properties in a non-destructive manner [7].

The study about the embrittlement of duplex stainless steels commonly used in components of nuclear plants can be attained by non-destructive testing based on the eddy current principle. This principle has been widely implemented because it uses light and compact equipment, and allows non-contact tests based on induced electromagnetic currents. For example, it allows the embrittlement quantification of duplex stainless steels by comparing the results of degraded and non-degraded materials [8]. On the other hand, studies about the precipitation of $\sigma$ phase in samples aged for times up to 2 hours at temperatures of $800{ }^{\circ} \mathrm{C}$ to $900{ }^{\circ} \mathrm{C}$ using this principle confirmed its effectiveness [9]. 
The phase transformations found in an UNS S31803 steel under temperatures below $550{ }^{\circ} \mathrm{C}$ are due to its spinodal decomposition mechanism. This mechanism consists of spontaneous decomposition of the ferrite matrix through fluctuations of composition, forming rich and poor regions in solute, which originates $\alpha^{\prime}$ phase in the rich regions. Over time, this phase coherent to the matrix loses the coherence. This transformation process has been observed by destructive and non-destructive techniques [5]. The formation of $\alpha^{\prime}$ phase in duplex stainless steels at temperatures range from $425{ }^{\circ} \mathrm{C}$ to $475{ }^{\circ} \mathrm{C}$ for times up to $200 \mathrm{~h}$ was studied based on measurements of sonic velocity attained using an industrial ultrasound equipment [10]. This technique revealed to be promising for the detection of $\alpha$ 'phase, which has nanometer dimensions.

The transformations of ferrite phase for temperatures up to $550{ }^{\circ} \mathrm{C}$ were also studied through measurements of magnetic susceptibility, and confirmed the possibility to monitor the decomposition mechanism of $\alpha$ phase for temperatures above $350{ }^{\circ} \mathrm{C}$ [11]. The samples of the duplex stainless steel were annealed at the temperatures of $350{ }^{\circ} \mathrm{C}, 450{ }^{\circ} \mathrm{C}, 475{ }^{\circ} \mathrm{C}$ and $550{ }^{\circ} \mathrm{C}$. It was observed that the curves of magnetic susceptibility along time decrease clearly at the beginning and then more smoothly for the annealing temperatures of $450{ }^{\circ} \mathrm{C}, 475{ }^{\circ} \mathrm{C}$ and 550 ${ }^{\circ} \mathrm{C}$; this behavior was not observed for the curve associated to the annealing temperature of $350{ }^{\circ} \mathrm{C}$. The steady state values of the curves for $450{ }^{\circ} \mathrm{C}$ and $550{ }^{\circ} \mathrm{C}$ were higher than the related value of the curve for $475^{\circ} \mathrm{C}$. This is because the decomposition of $\alpha$ phase occurs more rapidly at $475^{\circ} \mathrm{C}[11]$.

In a study based on magnetic susceptibility addressing an annealing temperature range between $400{ }^{\circ} \mathrm{C}$ and $600{ }^{\circ} \mathrm{C}$, it was found that the magnetic susceptibility decreases due to the presence of $\alpha^{\prime}$ phase. This phase is formed by spinodal decomposition mechanism, and as soon as the spinodal microstructure reaches the steady state growth, the sensitivity of the magnetic properties becomes weak [12]. 


\section{Experimental procedures}

In the present work, a Hall effect sensor was used for tracking the microstructural variations of the UNS S31803 duplex stainless steel in a non-destructive manner. The material samples were submitted to thermal aging at $425^{\circ} \mathrm{C}$ and $475^{\circ} \mathrm{C}$ for 0 (as-received) until $200 \mathrm{~h}$, which are the thermal conditions associated to the microstructural transformation of $\alpha^{\prime}$ phase. As such, the microstructural changes are the input data for the sensor, and the sensor voltage the output. The testing approach adopted showed to be simple, of low cost, and able to monitoring efficiently the microstructural variations of the material studied.

The samples of the UNS S31803 duplex stainless steel, with dimensions of 30x20x8 $\mathrm{mm}^{3}$, were aged at the temperatures of $425{ }^{\circ} \mathrm{C}$ and $475{ }^{\circ} \mathrm{C}$ during $12,24,48,100$ and 200 hours, and at the temperature of $525{ }^{\circ} \mathrm{C}$ for 200 hours, in order to track the formation of $\alpha^{\prime}$ phase. The heat treatment was performed in a resistance furnace with an uncontrolled atmosphere. The samples were placed in the furnace with the temperature already reached and then cooled in water after the aging. The aged samples and one in the condition as received were submitted to the Rockwell $\mathrm{C}$ hardness, X-ray diffraction (XRD) and magnetic permeability testing techniques. The first two are consolidated testing techniques and were used to validate the results obtained based on the magnetic measurements achieved by the non-destructive approach adopted. Particularly, the XRD tests were performed in order to identify the microstructural phases in the steel samples before and after the aging treatments.

Here, a study was conducted from the XRD spectra to examine the profile of the peak (200). Hence, the measurement of the width to half height was performed to examine the variation of the peak widening with the aging time. The measured values were then adjusted using the Non-linear Gauss method. 
The XRD equipment (SIEMENS D5000, Berlin, Germany) used was operated under the radiation parameters $\mathrm{k} \alpha$ of copper, with a voltage of $40 \mathrm{kV}$, current equal to $30 \mathrm{~mA}$, a step of $0.02^{\circ}$, and a time for step equal to $9.6 \mathrm{~s}$. The tests were performed adopting a scanning

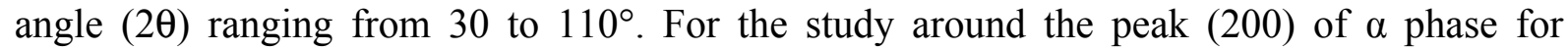

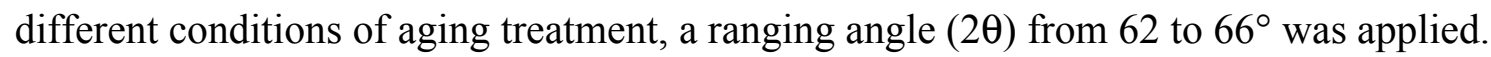

\section{Results}

The non-destructive tests were performed using an experimental setup consisted of a computer, a data acquisition board with a 10 bit analog digital converter, a power supply (DC), a testing workbench, a Hall effect sensor, and a permanent magnet, Figure 1. The sensor used (A1323L from Allegro MicroSystems, LLC (USA)) is a linear ratiometric type Hall-effect capable of operating under high temperatures. It contains a BiCMOS monolithic circuit with an integrated Hall element that provides high stability and sensitivity. The sensor's output voltage is proportional to the applied magnetic field [13].

A magnetic field of 430 Gauss was applied taking into account that the sensor used saturates at 600 Gauss, and the magnetic permeability $\mu$ was calculated based on the Hall tension according to:

$\mu=\frac{\left(V_{S}-2.5\right) \times 10^{3}}{S_{S} \times H}$

where $V_{S}$ is the output voltage in volts, 2.5 is the offset voltage, $S_{S}$ is the sensor's output sensitivity that is equal to $3.125 \mathrm{mVolts} /$ Gauss, and $H$ is the applied magnetic field in Gauss.

The micrograph of the duplex stainless steel as received is shown in Figure 2. The presence of austenite island $(\gamma)$ in the ferrite matrix $(\alpha)$ phase and the elongation of the grains due to rolling can be observed in this figure. It should be noted that in this steel, the $\gamma$ phase does not suffer any transformation during aging, only in $\alpha$ phase can suffer. Since the 
nanostructures formed under the studied conditions cannot be detected by Electronic Scanning Microscopy due to be very small and thin, we used X-ray diffraction in the microstructural characterization of the thermal aging samples in order to validate the findings obtained based on the magnetic permeability.

Figure 3 shows the X-ray diffraction measurements for the samples as received and aged for 200 hours at $525^{\circ} \mathrm{C}$. In this figure, only $\gamma$ and $\alpha$ phases are visible and variations in the peak (200) shape can be observed. Figures $4 \mathrm{a}$ and $4 \mathrm{~b}$ show the variations of hardness, permeability and width at half height for the samples aged at $425^{\circ} \mathrm{C}$ and $475{ }^{\circ} \mathrm{C}$, respectively. The width at half height is a measurement commonly used to follow the phase formed from $\alpha$ phase, and the results show a similar tendency relatively to the permeability. On the other hand, the hardness increases with time due to new formed phase.

\section{Discussion}

The microstructural transformation that occurs due to the thermal condition of aging time in duplex stainless steels can be characterized for two distinct regions: one for temperatures above $600{ }^{\circ} \mathrm{C}$, which corresponds to the formation of $\mathrm{Cr}_{2} \mathrm{~N}, \chi, \sigma$ and other phases; and another for inferior temperatures, with embrittlement found at temperatures of $475^{\circ} \mathrm{C}[14]$.

Here, the phase changes in temperatures ranging from $425^{\circ} \mathrm{C}$ to $525^{\circ} \mathrm{C}$ were studied. The X-ray diffraction of the samples as received and aged for 200 hours at $525{ }^{\circ} \mathrm{C}$ revealed the presence of $\gamma$ and $\alpha$ phases (Figure 3).

The temperature range studied is characterized by the decomposition of the initial $\alpha$ phase into two phases: a $\alpha$ phase poor in chromium and another $\alpha$ phase rich in chromium. The mechanism responsible for this transformation is the spinodal decomposition [15]. Under these conditions, $\gamma$ phase does not undergo any transformation [16]. 
The $\alpha$ phase decomposes spontaneously forming a phase called $\alpha^{\prime}$ that has a chemical composition close to the original phase composition. To be fully formed, this new phase aligns in the direction $<100>$, which has the lowest energy. The formation of this phase can be studied by the formation of side strips around the peak (200) of the X-ray diffraction of the $\alpha$ phase. It results in broadening of peak and reduced intensity. With the aim of studying the effect of these phenomena, the intensity of the peak at half height, which is an analysis parameter of formation of side strips, was analyzed [10].

For the samples aged at temperatures $425{ }^{\circ} \mathrm{C}$ and $475{ }^{\circ} \mathrm{C}$ (Figures $4 \mathrm{a}$ and $4 \mathrm{~b}$, respectively), the hardness results show the presence of two stages of hardening for the temperatures studied, each one with quite different rates of hardening. For the temperature of $425^{\circ} \mathrm{C}$, as the kinetics is slower, it was observed the first stage for times up to about $48 \mathrm{~h}$ and the beginning of second stage, and for $475^{\circ} \mathrm{C}$, which has a faster kinetic, the two stages of hardening were clearly observed, the first one up to about $24 \mathrm{~h}$. The increase of hardness due to the formation of $\alpha$ phase results in precipitates finely dispersed within the material matrix $[5,10]$

Measures of width and half height have been used for tracking microstructural transformations due to spinodal decomposition mechanism [5]. In duplex stainless steels at the temperatures studied in this work, just only microstructural transformations occur within the ferritic phase. The peak (200) of this phase suffers shape variations due to the formation of a new phase called $\alpha^{\prime}$ within the original $\alpha$ phase. An increase of the width half height was observed for aging times up to about $24 \mathrm{~h}$ (Figure $4 \mathrm{a}$ ). This increase is due to the formation of $\alpha^{\prime}$ phase and corresponds to the first stage of hardening. In this case, the hardening with a higher rate is due to the formation of $\alpha^{\prime}$ resulted from $\alpha$ prime phase, and the end of this phase formation was observed in the second hardening stage. 
The results of the magnetic permeability, calculated based on the Hall effect sensor's output voltages, had a behavior similar to the one of the width at half height measures, and were affected by the microstructural variations of the material under study. The sensor's output voltage is proportional to the density of the magnetic flux lines that reaches it. The magnetic permeability curves reveal significant reduction for aging times inferior to $50 \mathrm{~h}$ (Figure $4 b$ ), and tend to stabilize after this aging time due to the kinetics formation of $\alpha^{\prime}$ phase and its ferromagnetic characteristic. Similar results were also found in [11], where the phase transformations of a duplex stainless steel in the same range of aging temperatures were studied based on magnetic susceptibility. The authors found an initial drop of the magnetic susceptibility in the region of $\alpha^{\prime}$ phase formation, followed by a stabilization after the phase formation.

Some works have focused on the precipitation of microstructural phases in duplex steels by magnetic means and based on the volume variation of the ferrite phase $[17,18,19$, 20]. The volume fraction of ferrite phase in duplex stainless steels has been determined by ferritoscope tests $[9,14]$. The characterization of $\alpha^{\prime}$ phase in stainless steels based on the magnetic permeability found out that the precipitation of this phase by spinodal decomposition hampers the movement of the magnetic domain upon the application of an external field that causes the decrease of the permeability values [20,21].

\section{Conclusions}

The present study intended to verify the potential use of magnetic permeability measurements achieved using a Hall effect sensor. The results obtained confirmed that the Hall voltage measurements are affected by the phase transformations that occur in the UNS S31803 duplex stainless steel at the two temperatures studied $\left(425^{\circ} \mathrm{C}\right.$ and $\left.475{ }^{\circ} \mathrm{C}\right)$, and are suitable to track the formation of $\alpha^{\prime}$ phase in a non-destructive manner. This was confirmed by 
correlation with the X-ray diffraction technique that is an inspection technique already consolidated in this domain. Similar results were obtained by others authors that observed the decreasing in the magnetic susceptibility measurement in the same range of temperature. The microstructure formed hinders movement of magnetic domain walls and therefore, the magnetic susceptibility is decreased.

Based on the experimental findings, it is possible to conclude that the magnetic permeability can be used to continually monitor in service structures that are susceptible to embrittlement due to $\alpha$ phase transformations that cannot be easily detected by common destructive testing techniques, such as scanning electronic microscopy, and by nondestructive testing as ultrasound and eddy current techniques, due to the nanostructures formed be very small and thin. Additionally, in comparison to other non-destructive testing techniques, another attractive characteristic of this technique is that the permeability is an intrinsic property of the material that is not affected by geometry changes.

\section{Acknowledgments}

The authors acknowledge the financial support from Endesa/Aneel, and the full support of Federal Institute of Paraiba as well as of the Laboratory of Quick Solidification and of the Mechanical Engineering Department of the Federal University of Paraiba.

\section{References}

[1] Enokizono M, Tokada T, Tuchida Y, Hachiki N. Finite element analysis of moving magnetic flux type sensor developed for nondestructive testing. IEEE Transactions on Magnetics 1999; 35: 1853-1956.

[2] Bi Y, Jiles DC. Dependence of magnetic properties on crack size in steels. IEEE Transactions on Magnetics 1998; 34: 2021-2023. 
[3] Kosmas K, Sargentis Ch, Tsamakis D, Hristoforou E. Non-destructive evaluation of magnetic metallic materials using Hall sensors. Journal of Materials Processing Technology 2005; 161: 359-362.

[4] Cavalcante AF, Albuquerque VHC, Silva EM, Santos NC, Silva AA. A study of the application of a Hall sensor and an artificial neural network for recognition of different types of thermal treatment by which a SAE 1045 steel was subjected. In: Iberian Latin American Congress on Computation Methods in Engineering (XXIX CILANCE), November 4 to 7th, 2008, Maceio, Alagoas, Brazil.

[5] Silva EM, Albuquerque VHC, Leite JP, Varela ACG, Moura EP, Tavares JMRS. Phase Transformations evaluation on a UNS S31803 duplex stainless steel based on nondestructive testing. Materials Science and Engineering: A 2009; 516: 126-130.

[6] Ghosh SK, Mondal S. High temperature ageing behaviour of a duplex stainless steel. Materials Characterization 2008; 59: 1776-1783.

[7] Feritas VLA, Normando PG, Albuquerque VHC, Silva EM, Silva AA, Tavares JMRS. Nondestructive characterization and evaluation of embrittlement kinetics and elastic constants of duplex stainless steel SAF 2205 for different aging times at $425^{\circ} \mathrm{C}$ and $475^{\circ} \mathrm{C}$. Journal of Nondestructive Evaluation 2011; 30: 130-136.

[8] Maeda N, Yamaguchi A, Sugibayashi T, Kono K. Degradation detection of materials used in nuclear power plant components applying probe-type eddy current sensor. Part 1: Detection of thermal embrittlement in duplex stainless steel. Journal of JSNDI 1996; 45: 609-616.

[9] Normando PG, Moura EP, Souza JA, Tavares SSM, Padovese LR. Ultrasound, eddy current and magnetic Barkhausen noise as tools for sigma phase detection on a UNS S31803 duplex stainless steel. Materials Science and Engineering: A 2010; 527: 2886-2891. 
[10] Albuquerque VHC, Silva EM, Leite JP, Moura EP, Freitas VLA, Tavares JMRS. Spinodal decomposition mechanism study on the duplex stainless steel UNS S31803 using ultrasonic speed measurements. Materials \& Design 2010; 31: 2147-2150.

[11] Lo KH, Lai JKL. Microstructural characterisation and change in a.c. magnetic susceptibility of duplex stainless steel during spinodal decomposition. Journal of Nuclear Materials 2010; 401: 143-148.

[12] Lo KH, Lai JKL, Shek CH and Li DJ. Magnetic and transformation behavior of duplex stainless steel under non-isothermal conditions and temperature-fluctuation monitoring. Material Science and Engineering A 2007; 452-453: 149-160.

[13] ALLEGRO Microsystems. Available at: http://www.allegromicro.com/en.aspx. Accessed on: May 2012.

[14] Tavares SSM, Pardal JM, Guerreiro JL, Gomes AM, Da Silva MR. Magnetic detection of sigma phase in duplex stainless steel UNS S31803. Journal of Magnetism and Magnetic Materials 2010; 322: L29-L33.

[15] Iacoviello F, Casari F, Gialanella S. Effect of " $475^{\circ} \mathrm{C}$ embrittlement" on duplex stainless steels localized corrosion resistance. Corrosion Science 2005; 47(4):909-922.

[16] Mathew MD, Lietzan LM, Murty KL, Shah VN. Low temperature aging embrittlement of CF-8 stainless steel. Materials Science and Engineering: A 1999; 269: 186-196.

[17] Tavares SSM, Pedrosa PDS, Teodósio JR, Da Silva MR, Neto JM, Pairis S. Magnetic properties of the UNS S39205 duplex stainless steel. Journal of Alloys and Compounds 2003; 351: $283-288$

[18] Tavares SSM, Mello SR, Gomes AM, Neto JM, Da Silva MR, Pardal JM. X-ray diffraction and magnetic characterization of the retained austenite in a chromium alloyed high carbon steel. Journal of Material Science 2006; 41: 4732-4736. 
[19] Tavares SSM, Terra VF, Neto PL, Matos DE. Corrosion resistance evaluation of the UNS S31803 duplex stainless steels aged at low temperatures $\left(350\right.$ to $\left.550^{\circ} \mathrm{C}\right)$ using DLEPR tests. Journal of Materials Science 2005; 40: 4025-4028.

[20] Pardal JM, Tavares SSM, Fonseca MPC, da Silva MR, Ferreira MLR. Study of deleterious phase precipitation under continuous cooling of superduplex stainless steel UNS S32750. Materials Science and Technology 2012; 28: 295-302.

[21] Pardal JM, Tavares SSM, Fonseca MPC, da Silva MR, Neto JM, Abreu, HFG. Influence of temperature and aging time on hardness and magnetic properties of the maraging steel grade 300. Journal of Materials Science 2007; 42: 2276-2281 


\section{FIGURE CAPTIONS}

Figure 1: Experimental setup used for the non-destructive testing based on Hall effect: 1 Computer, 2 - Data acquisition board with a 10 bit analog digital converter, 3 - Power Supply (DC), 4 - Testing workbench, 5 - Hall effect sensor, 6 - Sample of the duplex stainless steel, 7 - Permanent magnet.

Figure 2: Optical microscopy of the duplex stainless steel sample as received (magnification of 1000X).

Figure 3: Diffractogram of the sample as received, showing only the presence of $\alpha$ and $\gamma$ phases (a), and of the aged sample at $550{ }^{\circ} \mathrm{C}$ for 200 hours (b).

Figure 4: Variation of the magnetic permeability, hardness and half height width for the material samples aged at $425^{\circ} \mathrm{C}$ (a) and at $475^{\circ} \mathrm{C}$ (b). 


\section{FIGURES}

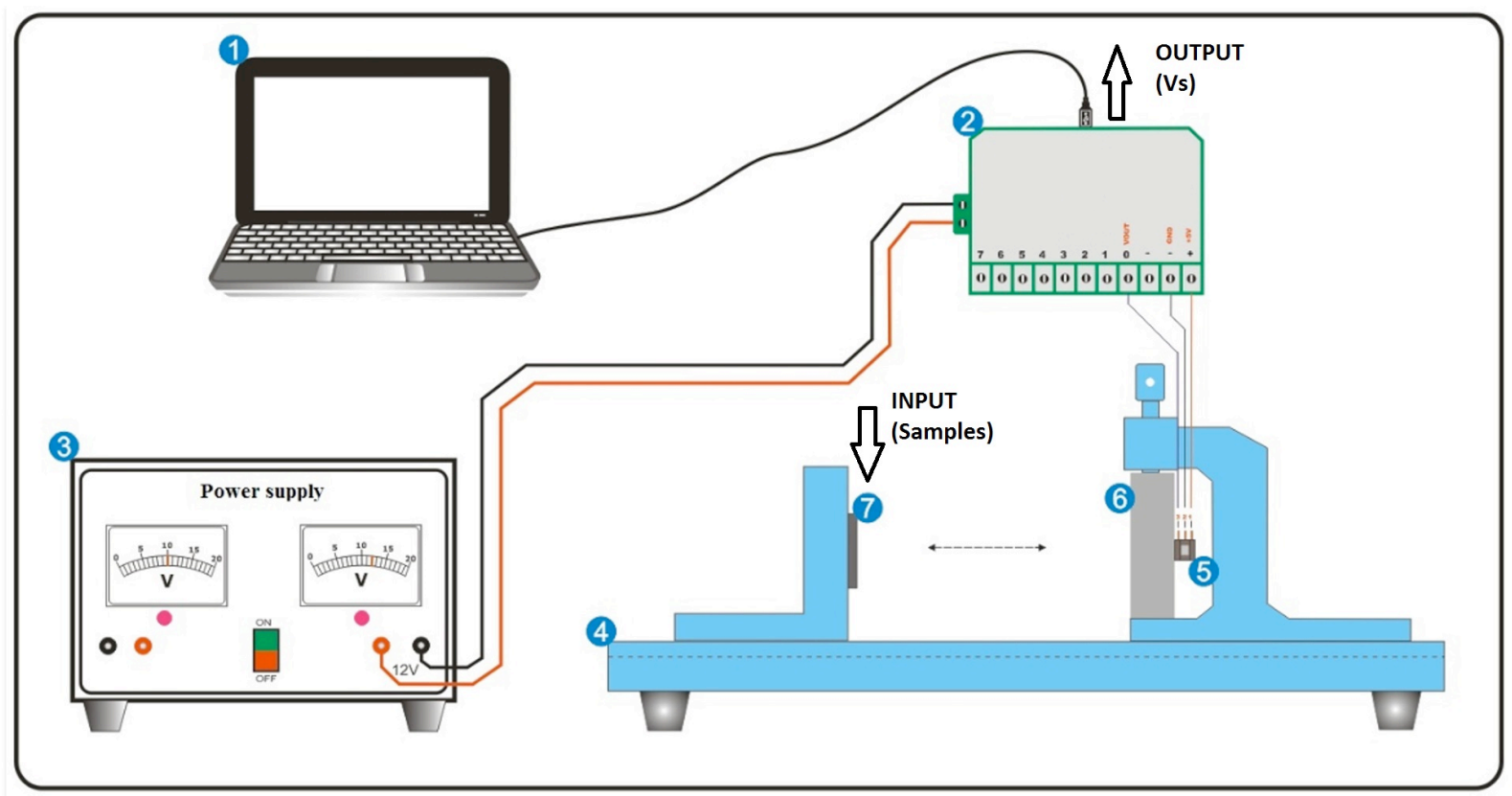

Figure 1

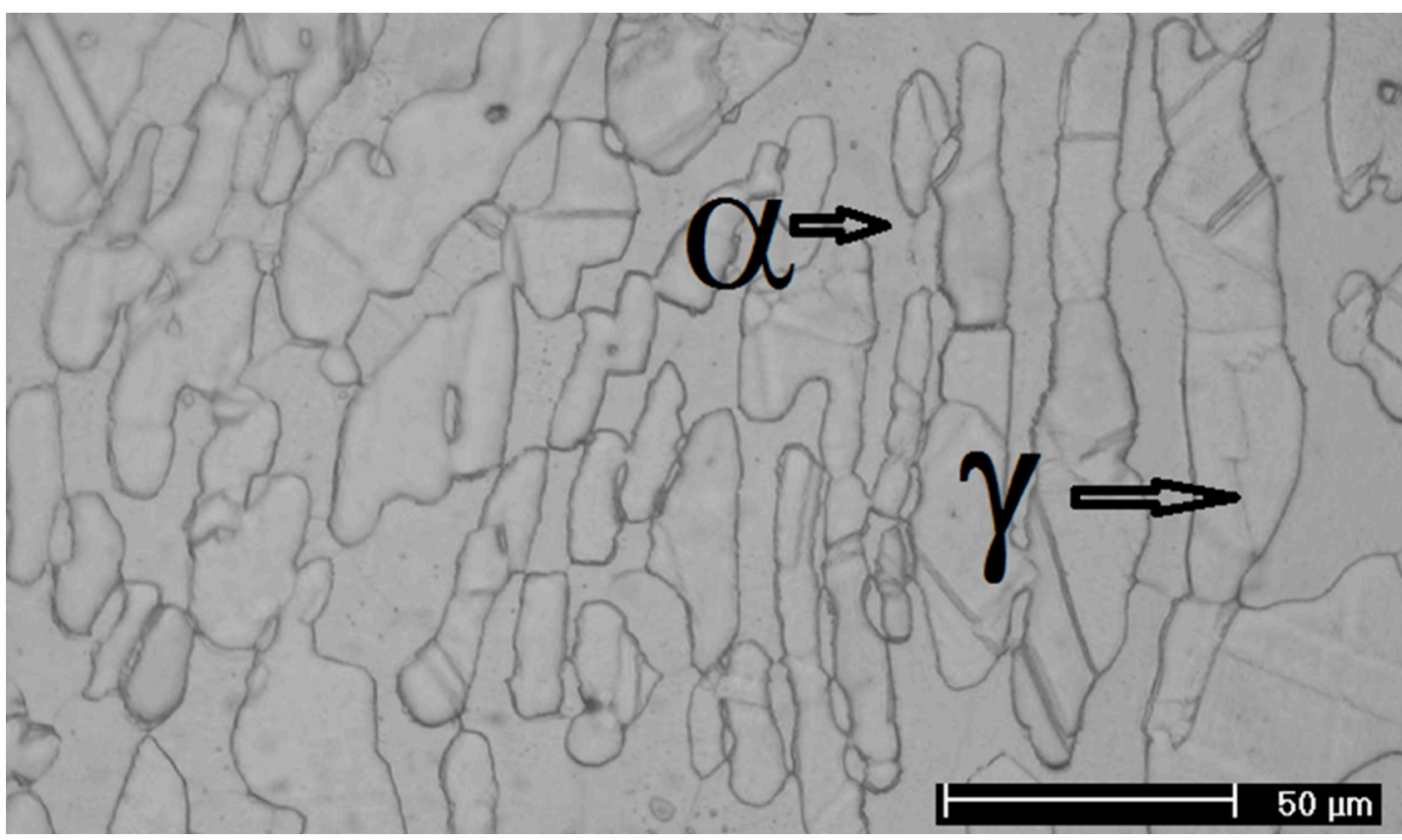

Figure 2 


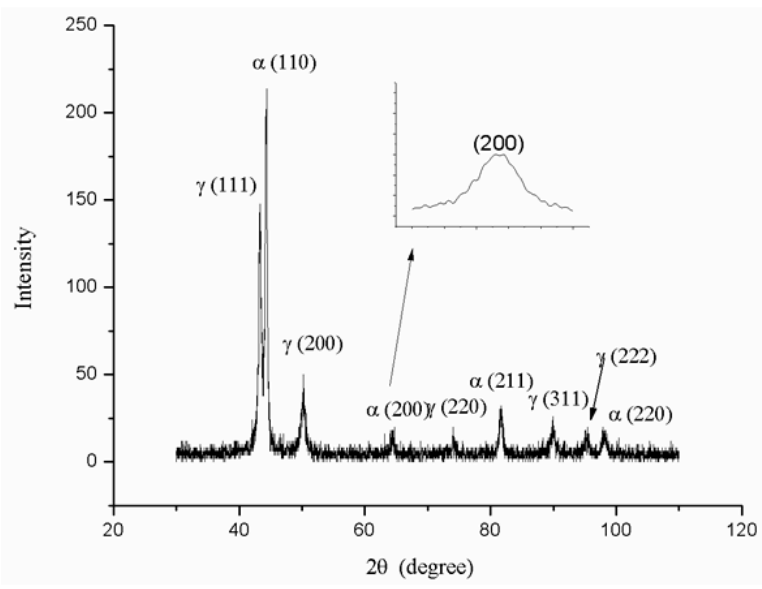

a)

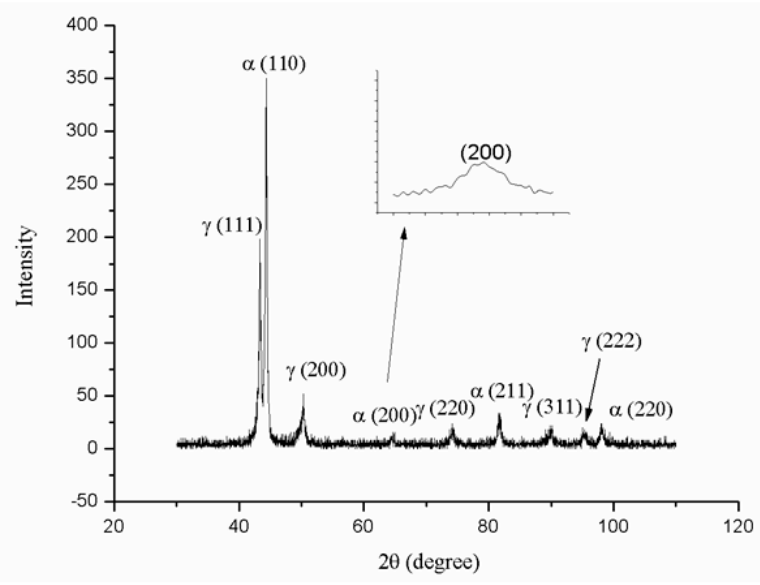

b)

Figure 3

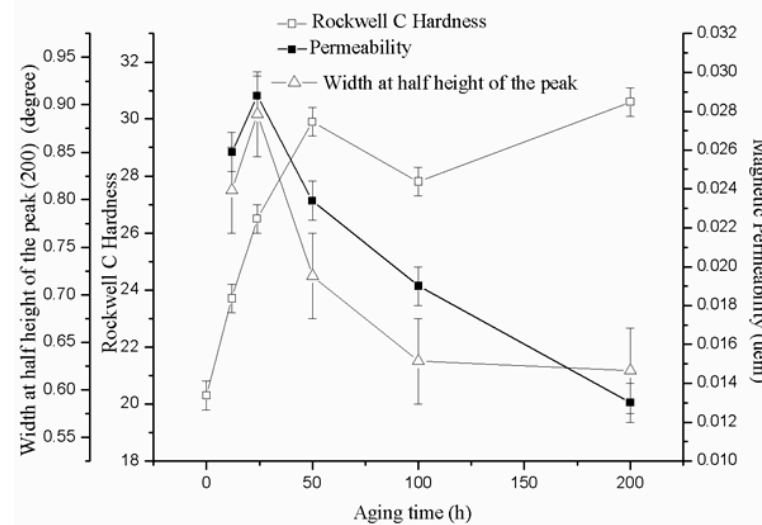

a)

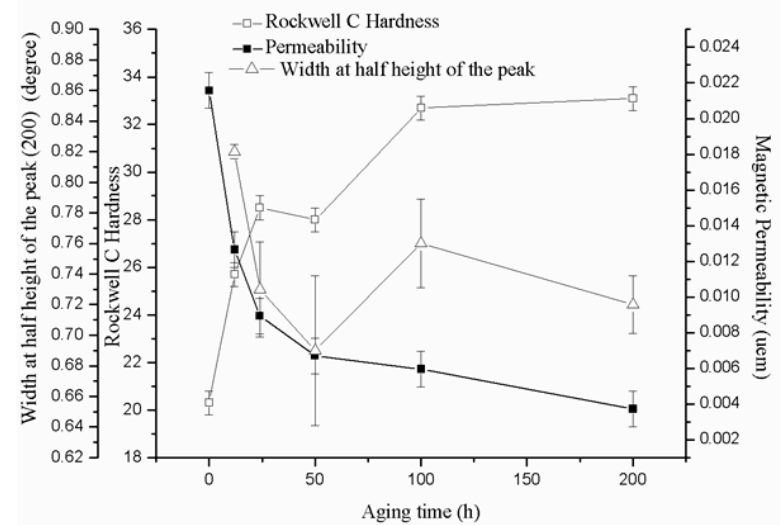

b)

Figure 4 